\title{
Compensatory Renal Growth in the Mouse. I. Allometric Approach to the Effect of Age
}

\author{
J. M. HUTSON, ${ }^{(50)}$ A. B. HOLT, K. EGAMI, M. NIALL, R. FOWLER, AND D. B. CHEEK \\ Department of Surgery and Research Foundation, Royal Children's Hospital, Melbourne, Australia
}

\begin{abstract}
Summary
Allometry, defined as the relationship between the growth rates of organs to the weight of the whole body (38), was used to study the effect of age on the degree of compensatory renal growth (CRG) in the mouse. The normal growth of the kidneys relative to body weight (BW) was determined in animals between 5 to 50 days of age. In one group, nephrectomy and sham operations were performed at 5,15 , and 35 days of age. The remaining ("renoprival") kidney was removed 15 days postnephrectomy. In a second group, nephrectomy was performed on 5-day-old animals, the renoprival kidney being removed after 30 or $\mathbf{4 5}$ days. Regression equations were calculated by least-squares after logarithmic transformation and different groups were compared by analysis of covariance. The regression equation for the control kidney was kidney weight $(\mathrm{KW})=0.0093 \mathrm{BW}^{0.86}(\mathrm{r}=0.96)$. The regression for renoprival kidneys in females was $\mathrm{KW}=0.0142 \mathrm{BW}^{0.83}(\mathrm{r}=$ $0.96)$ after 15 days and, in comparison, was not significantly different after 30 to 45 days. The intrval between control and renoprival regressions was equivalent to a difference of $\simeq 43 \% \mathrm{KW}$. In male mice, the regression for renoprival kidneys after 15 days was $\mathrm{KW}=0.0103 \mathrm{BW}^{0.96}(\mathrm{r}=0.98)$ and was not significantly different after 30 to 45 days. This study suggests that in young mice the time required for complete CRG may be a maximum of 15 days and that the amount of CRG does not depend on the age at operation. After CRG, a new equilibrium is reached which is therafter maintained up to a minimum of $\mathbf{5 0}$ days of age.
\end{abstract}

\section{Speculation}

Use of allometry to study compensatory renal growth suggests that the renoprival kidney grows rapidly until its mass is 70 to $75 \%$ of the normal total renal mass, after which its growth rate reaches an equilibrium with body weight. This precise degree of growth, which is known to occur mostly in the cortex, suggests the existence of a negative feedback loop regulating overall kidney weight when cortical mass (or function) is restored.

After nephrectomy, the remaining ("renoprival") kidney responds by increasing in size and function (30). Not only do nephrons increase in size $(2,22)$ but may, in the young animal, also increase in number $(5,21)$. Compensatory enlargement of the nephrons is due to a combination of cellular hyperplasia and hypertrophy. Hyperplasia is reported to be proportionally greater in the young $(6,14,25)$ than in the mature animal $(19,24)$. The overall size of the renoprival kidney is similarly reported to exhibit a greater increase in mass in young animals than in sexually mature adults $(1,3,14,17,22,26,27,36,42)$. However, this conclusion is not unanimous. There are reports of increasing compensatory renal growth (CRG) with age (2) and of no change with age (7-9). The methods of determining CRG vary widely, leading to confusion in interpretation and comparison of the different experiments.

There are two main reasons for the controversy over the effect of age on CRG. First, some authors do not allow for the normal, rapid growth of the kidney in neonatal animals when estimating CRG. This produces inflated estimates of growth stimulated by nephrectomy. Second, attempts to allow for differences in body size are usually based on the assumption that kidney weight (KW) increases in direct proportion to body weight (BW). However, the kidney normally grows at a slower rate than the whole body $(20$, 40). This results in the fact that CRG tends to be exaggerated in younger animals because the kidney is normally bigger relative to BW than in older animals.

Allometry, by mathematical definition, overcomes difficulties produced by changing proportionalities between organ weights and BW $(34,35,43)$. The two general forms of the allometric equation are the following:

$$
\begin{aligned}
y & =a x \\
\log y & =\log a+b \log x
\end{aligned}
$$

where $y$ and $x$ are variables such as $\mathrm{KW}$ and $\mathrm{BW}$, whereas a and $\mathrm{b}$ are constants. The relationship between $\mathrm{KW}$ and $\mathrm{BW}$ in rats has been shown to conform to this principle $(32,39,41,44,45)$, where:

$$
\mathrm{KW} \propto \mathrm{BW}^{0.75}
$$

Transformation of the data into logarithms by equation (B) allows the relationship between $\mathrm{KW}$ and $\mathrm{BW}$ to be expressed as a straight line, with a slope (b) of about 0.75 . Results from the equation indicate that the organ is growing faster than the whole body when slope $>1$; the organ is growing in direct proportion to the body when slope $=1$; the organ, e.g., the kidney, is growing slower than the body when slope $<1$.

The present study uses allometry to elucidate the relationship between the degree of CRG and age in the mouse up to 50 days of age.

\section{MATERIALS AND METHODS}

\section{ANIMALS}

Mice used in the experiment were normal heterozygotes of the C57BL/6J/lit mouse colony maintained at Royal Children's Hospital, Melbourne $(4,16)$. Food $(48)$ and water were freely available, although the younger mice were also able to suckle milk. The colony was maintained under constant environmental conditions with a room temperature of $22 \pm 1^{\circ} \mathrm{C}$, and a 12-hr light-dark cycle.

\section{SURGICAL TECHNIQUE}

All operations were performed with microsurgical instruments and an Olympus SZ dissecting microscope. Animals were weighed on a Mettler P1210 balance immediately before nephrectomy. Anaesthesia was induced with ether and maintained with halothane and oxygen delivered via a specially constructed head box. After a left loin incision, the kidney was gently mobilized, and the 
capsule was stripped; the ureter and vessels were then ligated at the hilum. The excised kidney was gently blotted and immediately placed in a weighed vessel. The wet $\mathrm{KW}$ was determined on a Mettler H54 balance. For sham nephrectomy, the kidney was exposed without mobilizing or stripping the capsule.

\section{EXPERIMENTAL DESIGN (FIG. l)}

The differences between right and left kidneys and the growth pattern of the kidneys relative to BW were determined in mice from 5 to 50 days of age. Nephrectomy was performed on two different groups of mice. In the first group, the left kidney was removed at 5,15 , or 35 days of age. The renoprival kidney was removed 15 days after each operation. Sham nephrectomies were performed at the same ages. Nephrectomies were performed at 5 days of age in the second group, with removal of the renoprival kidney for study either 30 or 45 days later. All subgroups had equal numbers of males and females.

\section{DATA ANALYSIS}

The allometric relationship between $\mathrm{KW}$ and $\mathrm{BW}$ was used after transforming the data into logarithms. Linear regression analysis was performed for $\log \mathrm{KW}$ versus $\log \mathrm{BW}$. Regression equations were calculated by the least-squares method using an Olivetti P602 minicomputer. The regression equations were compared by analysis of covariance, using a sequential $F$ test. The degree of CRG was determined by comparing regression lines for nephrectomized and control groups and by measuring the vertical interval between the two lines. The logarithmic interval between the regression lines, which was equivalent to a ratio between the (logarithmic) means of renoprival and control KW's, was then expressed as the percentage difference between the renoprival and control KW's. In the figures shown, the arithmetic values for KW and $\mathrm{BW}$ are plotted on log-log co-ordinates to simplify presentation of the logarithmic relations.

\section{RESULTS}

The right kidney was found to be heavier in 25 of 32 males and in 20 of 30 females ranging in age from 15 to 50 days. Nonpara-
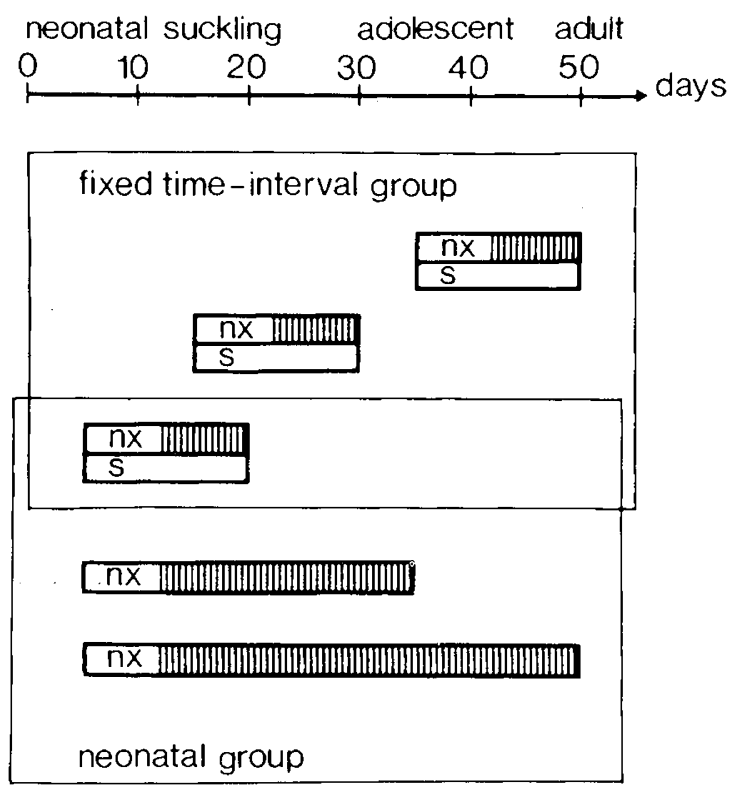

Fig. 1. Experimental protocol for nephrectomies $(n x)$ and $\operatorname{sham}(s)(s)$ operations for the fixed time interval (15 days) group and the neonatal group. The number of animals in each subgroup is shown on the right. The youngest group of animals is common to both groups for the purposes of calculation of regression equations. The age scale shows that the experiment spans all stages of development of the mouse. metric analysis (Wilcoxan) confirmed that right $\mathrm{KW}$ was significantly greater than left $\mathrm{KW}$ in both sexes, males $\left(\mathrm{T}_{32}=49 ; P<\right.$ $0.01)$ and females $\left(\mathrm{T}_{30}=119 ; P<0.05\right)$. This concurs with other studies on rodents $(2,9,22,29,36)$. Because of the difference between right and left $\mathrm{KW}$, only the right renoprival kidney was used for comparison to control kidneys.

Normal renal growth from 15 to 50 days of age was determined by linear regression analysis for the right $\mathrm{KW}$ (115 animals) and for the total KW (62 animals) (Fig. 2). The values for the correlation co-efficient ( $r$ ), regression slope (b), intercept (a), S.E. (slope), and S.E. (estimate) for control and renoprival kidneys are shown in Table 1. In general, the relationships studied exhibit " $r$ " values greater than 0.936 which indicate a strong linear dependence so that at least $87.5 \%$ of the variation in $\mathrm{KW}$ can be accounted for by the regression. (The values of " $F$ " determined by analysis of covariance are given in the figure legends.) No difference attributable to sex was found for right $\mathrm{KW}$ or for total $\mathrm{KW}$. The weights had regression slopes of $0.86(\mathrm{r}=0.96)$ and 0.89 $(\mathrm{r}=0.97)$, respectively (N.S.). No sex difference was found after sham left nephrectomy. There was no significant difference between the sham group (both sexes) and controls (both sexes), permitting the results after sham operation to be shown together with those of the controls in Figure 2.

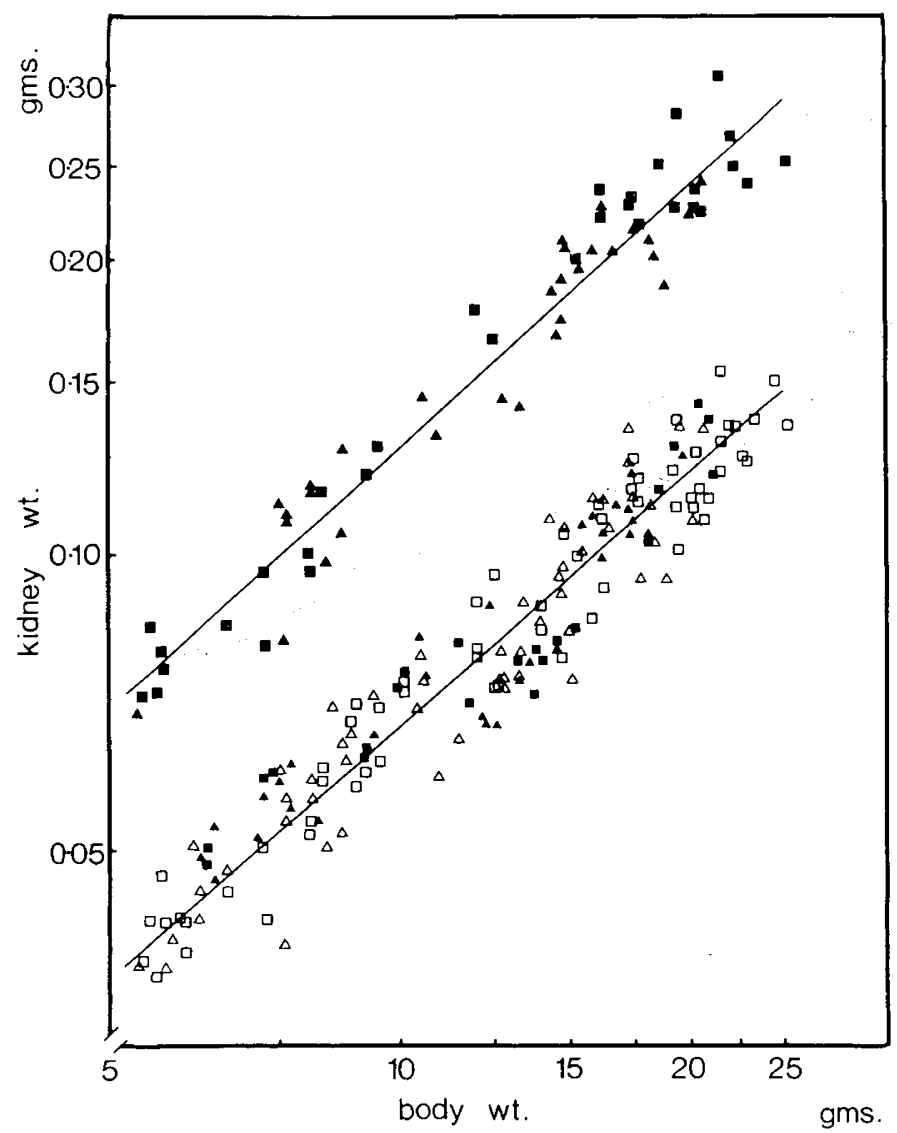

Fig. 2. Regressions of normal $\mathrm{KW}$ versus $\mathrm{BW}$. The upper line is for total $\mathrm{KW}$ [males (D), females $(\mathbf{A})$ ], and the regression equation is $\mathrm{KW}=$ $0.0166 \mathrm{BW}^{0.89}(\mathrm{r}=0.973)$. The lower line is for the right $\mathrm{KW}$ [males $(\square)$, females $(\triangle)$; the regression equation being $\mathrm{KW}=0.0093 \mathrm{BW}^{10.86}(\mathrm{r}=$ 0.964 ). The sham nephrectomies (males, small solid squares; females, small solid triangles) are shown with the control right kidney. There is no sex difference for right $\mathrm{KW}[F(2,111)=0.070$, N.S.] or for total $\mathrm{KW}[F(2,58)$ $=0.343$, N.S.]. The regressions for right $\mathrm{KW}$ and total $\mathrm{KW}$ are parallel $[F(2,173)=850 ; P<0.001$ for population difference; $F(1,173)=0.995$, N.S. for slope; $F(1,173)=1698 ; P<0.001$ for parallelism]. There is also no sex difference after sham nephrectomy $[F(2,49)=0.048$, N.S.], and comparison of the sham group (both sexes) with controls (both sexes) shows no difference $[F(2,164)=2.488$, N.S. $]$. 
Table 1. Parameters for regression equations calculated after logarithmic transformation

\begin{tabular}{|c|c|c|c|c|}
\hline & $\begin{array}{c}\text { No. of } \\
\text { animals }\end{array}$ & Slope (slope) & $\begin{array}{l}\text { Intercept (esti- } \\
\text { mated) }\end{array}$ & $\mathrm{r}$ \\
\hline \multicolumn{5}{|l|}{$\begin{array}{l}\text { Controls (both } \\
\text { sexes) }\end{array}$} \\
\hline Total KW & 62 & $0.892 \pm 0.027^{1}$ & $-1.780 \pm 0.031$ & 0.973 \\
\hline $\mathrm{R} T \cdot \mathrm{KW}$ & 115 & $0.856 \pm 0.022$ & $-2.029 \pm 0.024$ & 0.964 \\
\hline RT.KW (Sham) & 53 & $0.760 \pm 0.040$ & $-1.920 \pm 0.044$ & 0.936 \\
\hline \multicolumn{5}{|c|}{ 15-day interval nephrectomy (RT·KW) } \\
\hline Female & 42 & $0.828 \pm 0.037$ & $-1.848 \pm 0.040$ & 0.962 \\
\hline Male & 46 & $0.960 \pm 0.030$ & $-1.987 \pm 0.033$ & 0.979 \\
\hline \multicolumn{5}{|c|}{ Neonatal nephrectomy $(\mathrm{RT} \cdot \mathrm{KW})$} \\
\hline Female & 26 & $0.812 \pm 0.039$ & $-1.836 \pm 0.040$ & 0.973 \\
\hline Male & 32 & $0.938 \pm 0.033$ & $-1.957 \pm 0.034$ & 0.982 \\
\hline
\end{tabular}

${ }^{1}$ Mean \pm S.E.

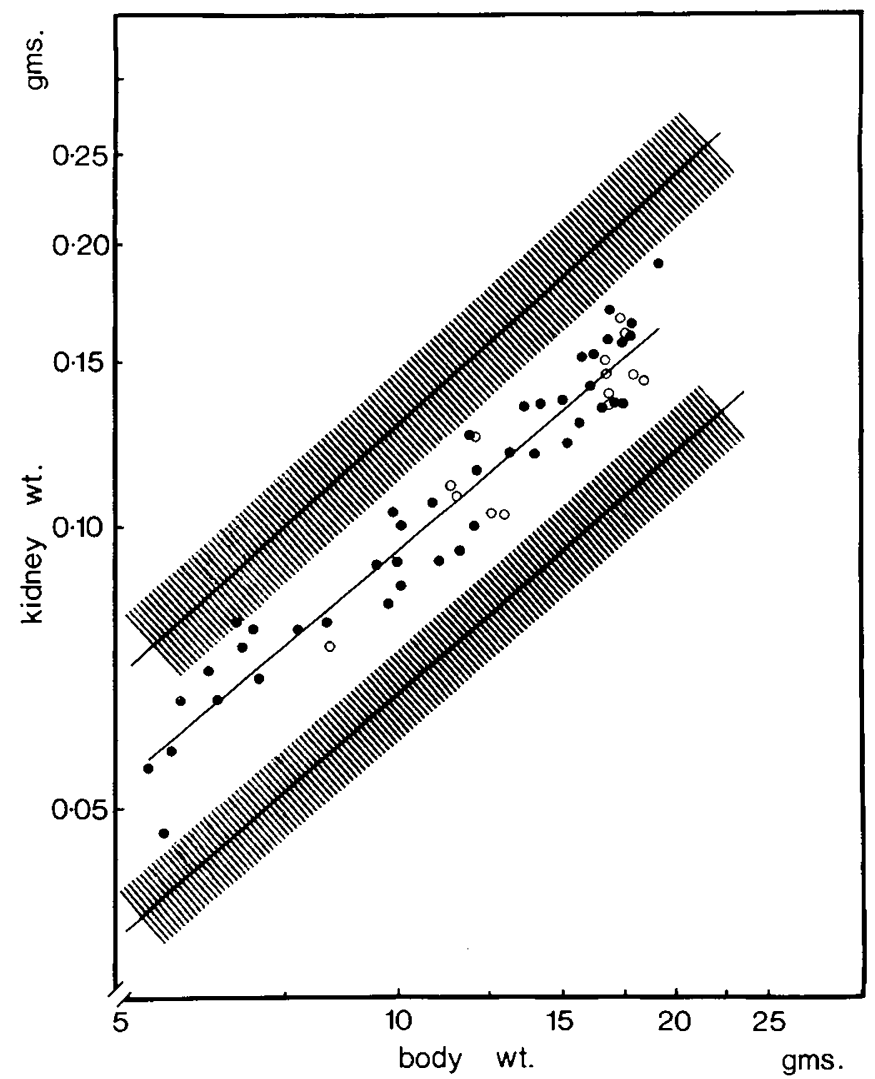

Fig. 3. Regression for the renoprival kidney in females [15-day interval $(\Theta)$; prolonged interval $(O)$ ]. The regression lines for the controls (right $\mathrm{KW}$ and total $\mathrm{KW}$ ) are shown with the cross-hatched areas representing \pm 2 S.D., such that about $95 \%$ of the control data would lie within these areas. The regression equation for the fixed time-interval renoprival group is $\mathrm{KW}=0.0142 \mathrm{BW}^{0.83}(\mathrm{r}=0.962)$. The regression for the renoprival kidney is parallel to that of the control right kidney $[F(2,153)=182 ; P<$ 0.001 for population difference; $F(1,153)=0.359$, N.S. for slope; $F(1,153)$ $=364 ; P<0.001$ for parallelism]. There is no significant difference between the regression for the renoprival kidneys after 15 days or more prolonged intervals $[F(2,64)=0.133$, N.S.].

The regression for the renoprival kidney in females (15-day interval) was $\mathrm{KW}=0.0142 \mathrm{BW}^{0.83}(\mathrm{r}=0.96)$. This line was parallel to that of the control right kidney $(P<0.001)$ (Fig. 3). The interval between the regression lines was equivalent to a difference of $\simeq 43 \%$ between renoprival and control kidneys. In females nephrectomized at 5 days of age, the regression for

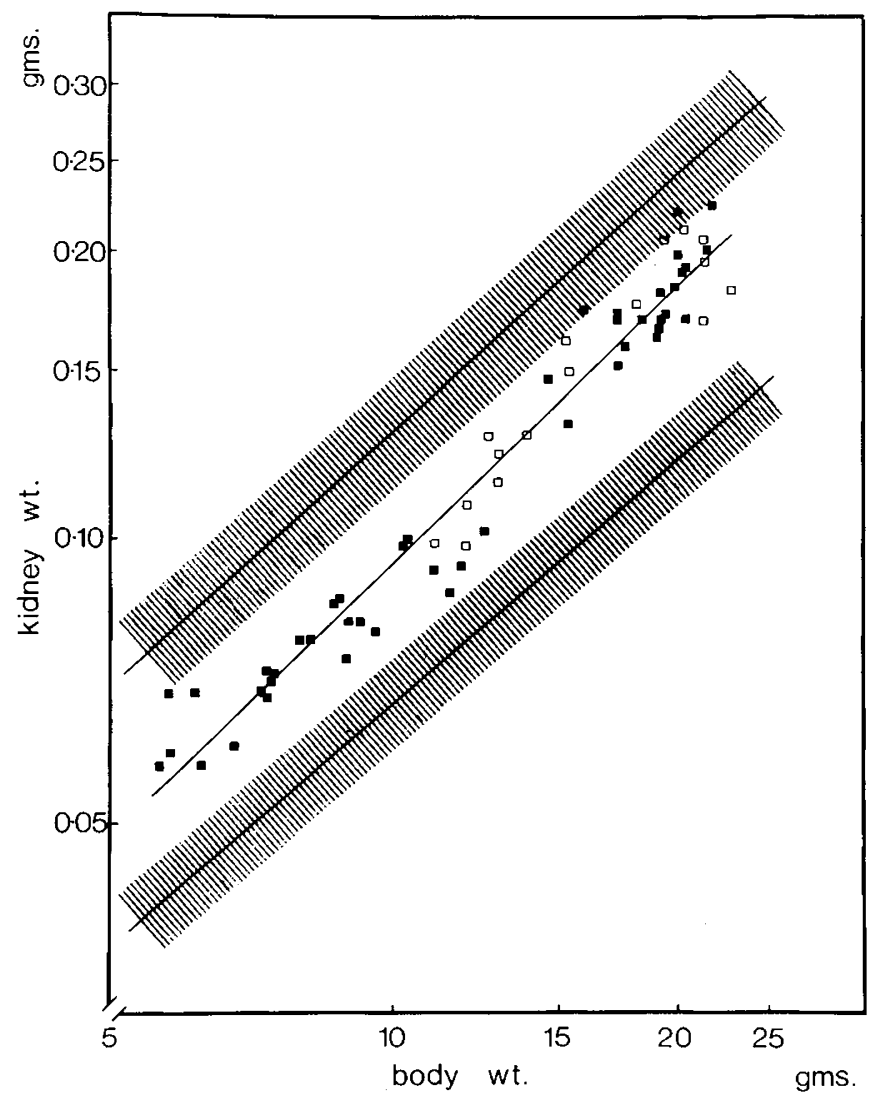

Fig. 4. Regression for the renoprival kidney in males [15-day interval (D); 30- to 45-day interval $(\square)$ ]. The regression lines for the controls (right $\mathrm{KW}$ and total $\mathrm{KW}$ ) are shown with the cross-hatched areas representing \pm 2 S.D., such that about $95 \%$ of the control data would lie within these areas. The regression equation for the 15-day interval renoprival group is $\mathrm{KW}=0.0103 \mathrm{BW}^{0.96}(\mathrm{r}=0.979)$. The renoprival and right control $\mathrm{KW}$ regressions have significantly different slopes $[F(2,157)=209 ; P<0.001$ for population difference, $F(1,157)=6.927 ; P<0.01$ for slope difference]. There is no significant difference between the regressions for the renoprival kidneys after 15 days or more prolonged intervals $[F(2,74)=$ $0.471, \mathrm{~N} . \mathrm{S}$.]. The slopes of the male and female renoprival $\mathrm{KW}$ regressions are significantly different $[F(2,84)=3.815 ; P<0.05$ for population difference; $F(1,84)=7.596 ; P<0.001$ for slope difference].

renoprival kidneys that were removed 15 to 45 days postnephrectomy was not significantly different from that obtained after a fixed interval of 15 days.

The regression for male renoprival kidneys (Fig. 4) after 15 days was $\mathrm{KW}=0.0103 \mathrm{BW}^{0.96}(\mathrm{r}=0.98)$. This regression line was not parallel to that of controls $(P<0.01)$ which suggests that the renoprival kidney was significantly bigger in 50-day-old animals than in 20-day animals. The regression line interval was equivalent to $\simeq 34 \% \mathrm{CRG}$ for neonatal animals and $51 \%$ for adolescent animals. There was a significant difference between the regression slopes for renoprival kidneys in males and females $(P<0.05)$. For 5-day-old males undergoing CRG, the regression for the renoprival kidney was not significantly different from that calculated after a fixed interval of 15 days.

\section{DISCUSSION}

Most investigators studying the effect of age on CRG have reported a greater degree of CRG in young animals $(1,3,14,17$, $22,26,27,36,42$ ), although allometry was not used. In some early reports, the small number of animals and conflicting results have hampered data interpretation. Arataki (2) compared rats nephrectomized at 20 or 50 days of age and found greater CRG in the older rats 50 days postnephrectomy. However, when both groups were compared at 100 days of age CRG was paradoxically greater 
in those nephrectomized at the younger age. Vérzar and Hugin (42) found CRG to be $140 \%$ after 30 days in 1- to 6-month-old rats, compared with 122 to $130 \%$ in animals aged 7 to 26 months. However, in 30 -month-old rats, CRG was $138 \%$. Jackson and Sheils (22) studied a small number of rats aged 6 or 26 days old and found $\mathrm{CRG}$ to be greater in the younger rats when compared with theoretical control weights derived from tables (15). Some workers, using animals with similar BW, have compared the mean $\mathrm{KW}$ of a group of renoprival kidneys with the mean $\mathrm{KW}$ of controls $(1,17,26)$. They report moderately greater $C R G$ in the younger animals. These calculations depend on an assumption of proportionality between $\mathrm{KW}$ and $\mathrm{BW}$ which is not necessarily supported by data $(32,39,41,44,45)$.

The ratio of $\mathrm{KW}$ per $100 \mathrm{~g} \mathrm{BW}(\%)$ has been used to compare neonatal and mature animals $(14,36)$, yet this percentage varies at different ages. Observations have confirmed that it decreases with age $(10,14,28,36)$. Inasmuch as this ratio is not fixed in relation to age, its use as a standard for comparing $\mathrm{CRG}$ at different ages is questionable (41). Mackay et al. (27) allowed for the slower growth of the kidney compared with BW by calculating it as a percentage of body surface area (SA). They (28) had previously reported that although $\mathrm{KW}$ per $100 \mathrm{~g} \mathrm{BW}$ diminished with increasing age, the ratio of $\mathrm{KW} / \mathrm{SA}$ remained roughly constant except in very small animals. The body SA was calculated from the equation $\mathrm{SA}=11.36 \mathrm{BW}^{0.66}$ (11). CRG was found to be greater in younger rats using the ratio $\mathrm{KW} / \mathrm{SA}$. However, the assumption that this ratio is always constant relative to age is disputed by Braun-Menendez (7) who found that it diminished with age. The formula for SA closely resembles the allometric equation $(32,39,41,44,45)$ but the power of 0.66 (for SA) is less than that found by allometry for KW $(0.75-0.80)$ in most strains of rats. Recently Aschinberg et al. (3l) reported greater CRG in puppies compared with older dogs. However, their results are not directly comparable with ours because $75 \%$ rather than $50 \%$ renal ablation was used, and thus, the older dogs developed a degree of renal failure.

No previous study has used log-log co-ordinates to derive the allometric relation for kidneys undergoing CRG. However, Braun-Menendez (7-9) used some of the principles of relative growth to study CRG and concluded that CRG remained constant relative to age. He plotted $\mathrm{KW}$ against $\mathrm{BW}$ on a linear scale (7) but recognized that the power function was a more accurate representation. Comparing pubertal and adult rats (8), he found $\mathrm{CRG}$ was effectively complete 2 to $3 \mathrm{wk}$ postnephrectomy. The renoprival kidney grew thereafter at a fixed rate relative to $\mathrm{BW}$.

The growth rate of the normal mouse kidney is slower than the whole body, although a slope of about 0.86 is greater than that for rats $(32,39,41,44,45)$. No differences are found between the sexes using allometry, even though the animals vary markedly in body size.

Use of allometry (Fig. 5) suggests that the time required for $\mathrm{CRG}$ in rodents may be much shorter than previously believed. Malt and Lemaitre (31) suggested that 60 to 70 days may be required in mice, whereas other workers have reported periods up to 120 days for rats $(2,22,37)$. This controversy resulted from the difficulty in defining the "end" of CRG and the resumption of "normal" growth. Our data suggest that, after a maximum of 15 days, the growth of the renoprival kidney reaches a new equilibrium in relation to BW. Thereafter, enlargement can be accounted by normal growth. The apparently greater CRG in 35-day-old males implies ongoing compensation, but the renoprival kidneys were the same weight as those from 5-day-old animals in only one-third of the time. A more likely explanation is that in both age groups CRG is "complete" but that the new normal growth rate of the male renoprival kidney is greater than in controls. The time required for the kidney to reach its new growth curve can now be defined as the "duration of CRG." It may be determined precisely by a plot of daily changes in $\mathrm{KW}$, which will show the point of intersection between the "compensatory" and normal growth curves.

The age at nephrectomy does not appear to influence the degree

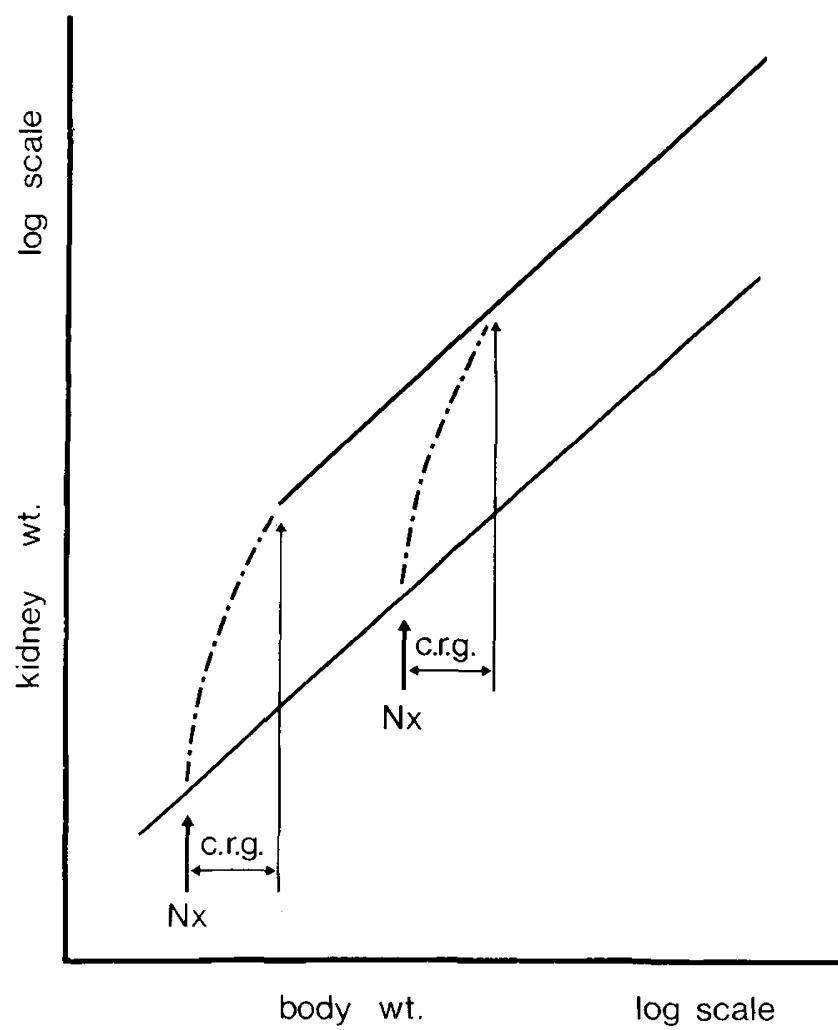

Fig. 5. Schema of normal and CRG. The lower (solid) line represents the normal growth of the kidney. After nephrectomy $(N x)$, the renoprival kidney grows rapidly (dotted line) until a new equilibrium is reached when growth becomes normal again (upper solid line). The dotted line is then equivalent to the phase of CRG. The time required for CRG appears to be no more than 15 days, an it is possible that the change in log body weight $(\log B W)$ which occurs simultaneously with CRG is constant, regardless of the age at nephrectomy. The renoprival kidney grows thereafter at the same rate, also independent of the age at nephrectomy. Because all animals have a finite maximum $\mathrm{BW}$, it is possible that if nephrectomy is performed at a time of maximum BW, CRG may not be maximal, as no simultaneous growth of the body can occur.

of CRG (the renoprival kidney reaches the same new equilibrium with $\mathrm{BW}$ in each case) even though total renal mass is not restored. The interval between the regression lines for renoprival $\mathrm{KW}$ and control $\mathrm{KW}$ was constant in females at $\simeq 43 \%$ and varied from $34 \%$ in young males to $51 \%$ in older males. The reason for this sex difference is not apparent, although it may be related to the renal growth-promoting effects of androgens (23).

Histologic studies show that CRG occurs predominantly in the cortex $(33,46)$. Goss (18) suggests that only "physiologically active" cortical tissue undergoes adaptive growth so that restoration of total renal mass is not necessary to restore the mass of the cortex. The predictable equilibrium that is reached after a phase of rapid growth supports the view that a negative feedback loop may be regulating cortical mass (or function) as has been concluded by others $(12,13)$.

The application of simple allometry leads to the conclusion that CRG in the young mouse is not age dependent, that the time required for adaptation may be less than 15 days, and that after the phase of CRG, the renoprival kidney reaches a new equilibrium with $\mathrm{BW}$.

\section{REFERENCES AND NOTES}

1. Addis, T., and Lew, W.: The restoration of lost organ tissue. J. Exp. Med., 71: 325 (1940).

2. Arataki, M.: Experimental researches on the compensatory enlargement of the surviving kidney after unilateral nephrectomy (albino rat). Am. J. Anat., 36: 437 (1926).

3. Aschinberg, L. C., Koskimies, O., Bernstein, J., Nash, M., Edelmann, C. M., Jr., and Spitzer, A.: The influence of age on the response to renal parenchymal 
loss. Yale J. Biol. Med., 51: 341 (1978).

4. Beamer, W. H., and Eicher, E. M.: Stimulation of growth in the little mouse. J. Endocrinol., 71: 37 (1976)

5. Bonvalet, J. P., Champion, M., Courtalon, A., Farman, N., Vandewalle, A., and Wanstok, F.: Number of glomeruli in normal and hypertrophied kidneys of mice and guinea pigs. J. Physiol. (Lond.), 269: 627 (1977).

6. Brasel, J. A.: Age dependant differences in DNA polymerase activity following uninephrectomy in rats. Growth, 36: 45 (1972).

7. Braun-Menendez, E.: El crecimiento del rinon. Rev. Soc. Argent. Biol., 22: 279 (1946).

8. Braun-Menendez, E.: El curso de la hipertrofia compensadora del rinon en la rata blanca. Rev. Soc. Argent. Biol., 22: 299 (1946).

9. Braun-Menendez, E.: Hypertension and the relation between body weight and kidney weight. Acta Physiol. Lat. Am., 2: 2 (1952).

10. Canter, C. E., and Goss, R. J.: Induction of extra nephrons in unilaterally nephrectomized immature rats. Proc. Soc. Exp. Biol. Med., 148: 294 (1975).

11. Carman, G. G., and Mitchel, H.: Estimation of the surface area of the white rat. Am. J. Physiol., 76: 380 (1926).

12. Dicker, S. E., and Morris, C. A.: Presence of a renotrophic factor in plasma of unilaterally nephrectomized rats. J. Physiol. (Lond.), 299: 13 (1980).

13. Dicker, S. E., Morris, C. A., and Shipolini, R.: Regulation of compensatory kidney hypertrophy by its own products. J. Physiol. (Lond.), 269: 687 (1977).

14. Dicker, S. E., and Shirley, D. G.: Compensatory renal growth after unilateral nephrectomy in the new-born rat. J. Physiol. (Lond.), 228:193 (1973).

15. Donaldson, H. H.: The rat: data and reference tables. Ed. 2 (Wistar Institute, Philadelphia, 1924)

16. Eicher, E. M. and Beamer, W. G.: Inherited ateliotic dwarfism in mice. Characteristics of the mutation, little, on chromosome 6. J. Heredity, 67: 87 (1976).

17. Galla, J. H., Klein-Robbenhaar, $T$., and Hayslett, J. P.: Influence of age on the compensatory response in growth and function to unilateral nephrectomy. Yale J. Biol. Med., 47: 218 (1974)

18. Goss, R. J.: Adaptive Growth, p. 50 (Logos, London, 1964).

19. Halliburton, I. W., and Thomson, R. Y.: Chemical aspects of compensatory renal hypertrophy. Cancer Res., 25: 1882 (1965)

20. Huxley, J. S.: Problems in relative growth. (Dial, New York, 1932).

21. Imbert, M. J., Berjal, G., Moss, N., De Rouffignag, C., and Bonvalet, J. P.: Number of nephrons in hypertrophic kidneys after unilateral nephrectomy in young and adult rats: a functional study. Pfluegers Arch. Eur. J. Physiol., 346: 279 (1974).

22. Jackson. C. M., and Shiels, M.: Compensatory hypertrophy of the kidney during various periods after unilateral nephrectomy in very young albino rats. Anat. Rec., 36: 221 (1927)

23. Jelsínek, J., Veselá, H., and Valová, B.: The effect of nortestosterone phenylpropionate on compensatory hypertrophy of the remaining kidney after unilateral nephrectomy. Acta Endocrinol., 46: 352 (1964).

24. Johnson, H. A., and Vera Roman, J. M.: Compensatory renal enlargement. Hypertrophy versus hyperplasia. Am. J. Pathol., 49: 1 (1966).

25. Karp, R., Brasel, J. A., and Winick, M.: Compensatory kidney growth after uninephrectomy in adult and infant rats. Am. J. Dis. Child., 121:186 (1971)

26. Kaufman, J. M., Hardy, R., and Hayslett, J. P.: Age dependent characteristics of compensatory renal growth. Kidney Int. 8: 21 (1975)

27. MacKay, E. M., MacKay, L. L., and Addis, T.: The degree of compensatory renal hypertrophy following unilateral nephrectomy. I. The influence of age. J. Exp. Med.: 56: 255 (1932).

28. MacKay, L. L., and MacKay, E. M.: Factors which determine renal weight. II. Age. Am. J. Physiol., 83: 191 (1927).
29. MacKay, L. L., and MacKay, E. M.: The difference in the weight of the left and right kidneys. Growth, I: 309 (1937).

30. Malt, R. A.: Compensatory growth of the kidney. N. Engl. J. Med., 280: 1446 (1969).

31. Malt, R A, and LeMaitre, D. A: Accretion and turnover of RNA in the renoprival kidney. Am. J. Physiol., 214: 1041 (1968).

32. Potter, D., Jarrah, A., Sakai, T., Harrah, J., and Holliday, M. A.: Character of function and size in kidney during normal growth of rats. Pediatr. Res., 3: 51 (1969).

33. Rollason, H. D.: Compensatory hypertrophy of the kidney of the young rat with special emphasis on the role of cellular hyperplasia. Anat. Rec., 104: 263 (1949).

34. Savageau, M. A.: Growth of complex systems can be related to the properties of their underlying determinants. Proc. Nat. Acad. Sci. U. S. A.. 76: 5413 (1979).

35. Savageau, M. A.: Allometric morphogenesis of complex systems: Derivation of the basic equations from first principles. Proc. Natl. Acad. Sci. U. S. A., 76: $6023(1979)$

36. Shirley, D. G.: Developmental and compensatory renal growth in the guinea pig. Biol. Neonate, 30: 169 (1976).

37. Smith, A. H., and Moise, T. S.: Diet and tissue growth. IV. The rate of compensatory renal enlargement after unilateral nephrectomy in the white rat. J. Exp. Med., 45: 263 (1927)

38. Snell, O.: Die Abhangigkeit des Hirngewichtes von dem Korpergewicht und den geistigen Fahagkeiten. Arch. Psychiatr., 23: 436 (1892).

39. Stoerk, H. C., and Zucker, T. F.: Relative growth of the kidney in male rats. Proc. Soc. Exp. Biol. Med., 61: 297 (1946).

40. Thompson, D. W.: On growth and form. (Cambridge University Press, Cambridge, 1917).

41. Trieb, G., Pappritz, G., and Lützen, L.: Allometric analysis of organ weights. 1. Rats. Toxicol. Appl. Pharamcol., 35: 531 (1976).

42. Verzár, F., and Hügin, E. Einfluss des Alters auf die Entwicklung der Arbeitshypertrophie von Organen: kompensatorische Hypertrophie der Niere und der Nebenniere. Acta Anat., 30: 918 (1957).

43. von Bertalanffy, L. von: Principles and theory of growth. In: W. W. Nowinsky: Fundamental Aspects of Normal and Malignant Growth. p. 244 (Elsevier, Amsterdam, 1960).

44. von Bertalanffy, L., and Pirozynski, W. J.: Ontogenic and evolutionary allometry. Evolution, 6: 387 (1957)

45. Walter, F., and Addis, T.: Organ work and organ weight. J. Exp. Med., 69: 467 (1939).

46. Williams, G. E.: Some aspects of compensatory hyperplasia of the kidney. Br. J. Exp. Pathol., 42: 386 (1961).

47. The contents of this paper were presented in part at the 5th International Pediatric Nephrology Symposium, Philadelphia, PA, October 1980.

48. "Mecon Rat and Mouse Cubes" (Nafag formulation containing 22\% protein), Fidelity Feeds, Melbourne, Australia

49. The authors wish to thank Donald Evans for excellent technical assistance, Cheryl Robinson, and Karen DelVecchio for typing the manuscript. We are indebted to Dr. A. Parra, Head, Protein Hormone Section, Instituto Mexicano del Seguro Social, Mexico City, for translating two of the references.

50. Requests for reprints should be addressed to: Dr. John M. Hutson, \% Division of Pediatric Surgery, Massachusetts General Hospital, Boston. MA 02114 (USA).

51. This research was supported in part by grants from the Australian Kidney Foundation and Felton Bequest.

52. Received for publication July 15,1980

53. Accepted for publication February 1, 1981 